\title{
Afetos e arranjos de um clube de amigos
}

\author{
Luã Ferreira Leal
}

\section{Resenha de:}

DINIZ, Sheyla Castro. "...De tudo que a gente sonhou": amigos e canções do Clube da Esquina. São Paulo: Intermeios, Fapesp, 2017.

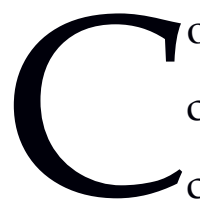

omo os rios que nascem em Minas Gerais, o livro resenhado resplandece como caudalosa fonte de inspiração para novos estudos sobre compositores e intérpretes no Brasil. Versão revisada da dissertação de mestrado, defendida em 2012 no Programa de Pós-Graduação em Sociologia da Unicamp, "...De tudo que a gente sonhou": amigos e canções do Clube da Esquina se insere no rol de reavaliações sobre o impacto do lançamento do Clube da Esquina, o primeiro álbum duplo de estúdio gravado no Brasil. A análise efetuada, apoiada em conceitos de Raymond Williams como estrutura de sentimento e formação cultural, propicia reflexões a respeito da criação de formas de pertencimento. A proposta inicial é tentar definir o que foi o Clube da Esquina: um movimento musical, apenas o título de canções e álbuns ou uma turma informal de compositores e instrumentistas?

O Clube da Esquina, de acordo com o argumento central do livro, não se caracterizou inicialmente como movimento, mas uma comunidade de jovens artistas que propiciou uma "movimentação". A "turma de amigos" foi uma formação cultural com identificação grupal manifestada ocasionalmente, sem registro formal (p.97) ${ }^{1}$. Transfronteiriços, o livro resenhado e o objeto de sua análise jamais ficam circunscritos a apenas um tipo de classificação. Ao adotar uma combinação de métodos de pesquisa - com análise das capas e das canções dos álbuns -, a autora

\footnotetext{
* Luã Ferreira Leal é Mestre e doutorando do Programa de Pós-Graduação em Sociologia da Unicamp. Integrante do Grupo de Estudos em Bourdieu (GEBU) do IFCH/Unicamp. Entre 2015 e 2019, foi bolsista da Fapesp para o desenvolvimento da pesquisa "O 'popular' na pauta da Academia Brasileira de Música".

${ }^{1}$ A inspiração teórica é a formulação conceitual de Raymond Williams sobre "cultural formation". Em seu livro The Sociology of Culture, publicado originalmente em 1981, ele dedica um capítulo para analisar tal conceito que ajuda a entender as relações sociais entre gerações de artistas e intelectuais.
} 
demonstra como os amigos do Clube realizavam musicalmente algo "inclassificável". Com impasses e contradições, a consagração desse grupo de artistas, em sua maioria oriundos de Minas Gerais, demonstrou como as tentativas de definição forjaram um grande desafio, inclusive para quem participou dessa formação cultural.

A banda Som Imaginário, criada em 1969, acompanhou Milton Nascimento em turnê e, no ano seguinte, com seus integrantes Wagner Tiso, Zé Rodrix, Naná Vasconcelos, entre outros, participou do LP Milton. Em entrevista publicada em junho de 1972, Milton Nascimento criticou quem definiu sua atuação musical com a banda Som Imaginário como "toada mineira". Na análise dessa entrevista do intérprete e compositor, percebe-se que havia um esforço dele para não aprisionar a atividade artística dentro de apenas uma categoria, bem como para diferenciar-se de outros compositores como Chico Buarque, Edu Lobo e os tropicalistas. No capítulo intitulado "Clube da Esquina 'versus' Tropicalismo", a autora demonstra quais foram as tensões nas batalhas pela consagração, fomentadas pela imprensa especializada, entre quem era considerado "careta" ou "inovador". A esses conflitos simbólicos (p.95), relacionados a classificações engendradas pela crítica musical, foram sobrepostas interpretações a respeito da diferenciação, refutada pelos artistas, entre os "baianos" e os "mineiros", ou seja, entre tropicalistas e quem se "filiou" à comunidade de amigos do Clube da Esquina.

Márcio Borges, em 2010, declarou em entrevista que a "essência" da identidade cultural e política de Minas Gerais é a liberdade. Essa característica, nas disputas pelas memórias daquele período, foi retomada exatamente para não isolar a canção de protesto ou o tropicalismo como expressões musicais críticas à ditadura militar. Com suas respostas à repressão, que restringia a liberdade criativa, o Clube da Esquina, mesclando referências à tradição e à modernidade, forjou laços de pertencimento de um grupo habilitado a pensar a identidade, não somente em termos "regionais" ou "nacionais". Essa preocupação em não se aprisionar ao gentílico, usado por quem designava a turma de amigos como os "mineiros", faz lembrar um verso da canção “Para Lennon e McCartney" do LP Milton (1970): “Sou do mundo, sou Minas Gerais". 
Uma possível leitura do processo de reorganização do mercado fonográfico na década de 1970 ajuda a pensar que a redefinição das fronteiras alterou o que era classificado pelo Clube como regional ou nacional, local (provinciano) ou universal. Nas canções, havia uma concepção de "povo", seja o mineiro, seja o latinoamericano, que entendia essa entidade como reserva da autenticidade, conjunto de figuras simples do cotidiano (p.38) com nobres sentimentos. Com as novas "possibilidades estéticas", propiciadas pelas parcerias do grupo, à mineiridade foram adicionados matizes da América Latina como tema do repertório musical desde o final da década de 1960. A repressão limitava a criação, mas também havia se tornado questão indispensável para quem quisesse interpretar a realidade social do Brasil e dos demais países latino-americanos.

Outro ponto do livro precisa ser ressaltado a respeito das relações entre artistas e críticos de música. Apesar de ter obtido o maior nível de notoriedade e prestígio como artista, Milton Nascimento jamais assumiu oficialmente a liderança de um "grupo mineiro" produtor de música "regional". A crítica especializada em música popular, quando não estava comparando o Clube da Esquina com outros grupos ou "movimentos", se assombrava com a sua condição de inclassificável. Na seção de "Discos" da revista O Cruzeiro, Clube da Esquina foi um álbum definido como "irresumível", "uma viagem, uma excursão pelo mundo de Milton e de seus amigos" (p.123). Críticos da revista Rolling Stone, ao compararem o álbum com Tropicália, consideravam pouco inventiva ou uma "chatice mastodôntica" (p.126) a atividade artística de Milton Nascimento, Fernando Brant e Lô Borges.

As formas de oposição ao sistema político não se restringiam às canções de protesto dos compositores "engajados" de sucesso nos festivais da canção, pois o Clube da Esquina “conjugou" o engajamento com expressões da contracultura (p. 93). As experiências contraculturais dessa turma de amigos, portanto, não implicaram alheamento, escapismo e individualismo, apesar dessa estigmatização sofrida pelos adeptos do desbunde. O grupo havia se formado com uma concepção sobre o "povo" como aliado das transformações sociais, um “romantismo revolucionário" (p.66) que jamais abandonou os contornos da identidade (mineiridade, brasilidade ou 
latinidade) ${ }^{2}$. Os "mineiros", na década de 1970, imprimiram novas marcas, como diálogo com o rock, experimentalismo, oposição à ditadura e difusão da contracultura, à sua atividade musical.

Milton Nascimento, inicialmente, recebeu reconhecimento e prestígio nos concursos como o II Festival da MPB na TV Excelsior (1966) e do II Festival Internacional da Canção (1967). Sua carreira, no entanto, se transformou com o grupo de amigos, formado originalmente em Belo Horizonte, com gostos, experiências e trajetórias heterogêneos. Os três primeiros discos de Milton, caracterizados pela ênfase à mineiridade e ao "ideário nacional-popular" (p.70), se diferenciam de outras produções como Clube da Esquina (assinado em parceria com Lô Borges), álbum que, para a autora do livro, expressa a combinação do despojamento, da informalidade, da coletividade, do espírito lúdico e da espontaneidade na música e nas relações de amizade.

Desde o início da década de 1970, a cenografia e os figurinos das performances provocaram alteração na construção da imagem artística de Milton Nascimento. A análise do Clube da Esquina permite compreender algumas estratégias da indústria fonográfica, em contexto de reformulação do mercado da música. Os três primeiros álbuns de Milton Nascimento foram produzidos anualmente entre 1967 e 1969. Em 1972, a EMI-Odeon lançou Clube da Esquina, no ano seguinte, Milagre dos peixes, em 1974, Milagre dos peixes ao vivo com a banda Som Imaginário, e, em 1978, Clube da Esquina 2, quando Milton Nascimento gravou "rodeado de artistas renomados" (p. 209). A autora cita o depoimento de Márcio Borges sobre o Clube da Esquina 2 ser uma "superprodução", pois no estúdio havia "estrelas demais, tietagem demais", o que resultou em um clima de gravação distinto ao do álbum homônimo de 1972, marcado por maior autonomia de instrumentistas e letristas.

\footnotetext{
2 Sheyla Diniz retoma uma formulação conceitual também adotada pelo orientador de sua dissertação e de sua tese, Marcelo Ridenti, a respeito do "romantismo revolucionário". Ele, por sua vez, cita em vários de seus textos Michael Löwy e Robert Sayre, autores do livro Revolta e melancolia - o romantismo na contramão da modernidade (Editora Vozes, 1995). O conceito, em trabalhos de Ridenti como Em busca do povo brasileiro: artistas da revolução, do CPC à era da TV (Record, 2000), serve para pensar a convergência entre política e cultura, vida pública e privada na atividade de intelectuais e artistas na década de 1960 (cf. RIDENTI, Marcelo. Intelectuais e romantismo revolucionário. São Paulo em Perspectiva, vol.15, n.2, p.13-19, 2001).
} 
O despojamento e o espírito de coletividade foram traduzidos tanto no modo de organizar as atividades musicais desse grupo quanto nas relações sociais. Com fotografias de pessoas envolvidas com o trabalho de produção, amigos e parentes, registradas por Juvenal Pereira, o encarte do álbum de 1972 serve também como capa do livro "...De tudo que a gente sonhou". Várias canções foram compostas enquanto Milton Nascimento e seu primo “Jacaré”, Lô Borges e Beto Guedes moraram juntos em uma casa em Mar Azul, na praia de Piratininga, expressão de um modo comunitário de pertencer à "turma de amigos". Além de nomes dos álbuns, de 1972 e 1978, Clube da Esquina, portanto, foi uma formação cultural, uma rede de “sociabilidades compartilhadas em diversos espaços" (p.49).

Com menor peso nas historiografias acadêmica e não acadêmica da música popular brasileira, em comparação com tropicalistas e bossa-novistas, o Clube da Esquina, ao ser analisado, permite que sejam compreendidas as condições que tornaram possível o aumento do prestígio desses compositores e intérpretes durante a modernização autoritária do mercado de bens simbólicos no Brasil. Os álbuns e os shows Milagre dos peixes - cuja dimensão política foi percebida pelos órgãos de censura - foram os pontos de inflexão na carreira e na persona artística de Milton Nascimento ${ }^{3}$. Para o álbum duplo Milagre dos Peixes, de 1973, Milton Nascimento convidou vários de seus “amigos e parceiros mais assíduos" (p.140), como Márcio Borges, Ronaldo Bastos, Naná Vasconcelos, Fernando Brant, entre outros, mostrando assim a perenidade dessas relações amistosas e artísticas. Fornecendo prestígio e lucro para a EMI-Odeon, os álbuns de Milton Nascimento Minas e Geraes, embora distintos, se complementavam, pois formavam uma unidade composta por partes opostas (p.189); nas palavras de Ronaldo Bastos eram "discos gêmeos" (p.208). Em Minas (1975), de proposta experimental, há diferentes fusões musicais, com recorrente presença da guitarra e do contrabaixo elétrico. Com Geraes (1976), a mineiridade encontrou a latinidade pelas expressões do imaginário sobre o

\footnotetext{
${ }^{3}$ Durante a década de 1970, cada vez menos a persona de Milton combinava com os ares de informalidade e de despojamento do Clube da Esquina. Também em 1973, a gravadora Continental passou a promover outro agrupamento de artistas atrelado a um topônimo: o LP Pessoal do Ceará. Além de Rodger, Ednardo e Tetty, reunidos nesse álbum, essa categoria passou a definir, segundo a crítica especializada, o boom nordestino com Marcus Vinícius, Fagner e Belchior (cf. MORELLI, Rita de Cássia Lahoz. Indústria fonográfica: um estudo antropológico. 2. ed. Campinas, SP: Editora da Unicamp, 2009, p. 80).
} 
povo (p.185), movimento reiterado com Clube da Esquina 2, sobretudo nas faixas “Casamiento de negros" e "Canción por la unidad de Latino America".

A quem for ler "...De tudo que a gente sonhou", recomenda-se acompanhar como o problema sociológico foi construído e de que maneira foram selecionados determinados dados (capas e contracapas de discos, letras, arranjos, harmonia, instrumentação e melodias de canções) que corroboraram cada argumento. Questão suscitada, mas não debatida em termos teóricos, a memória coletiva parece ser um elemento subjacente a todos os capítulos do livro. A "reavaliação histórica" (p.25) sobre o passado do Clube se propagou exatamente quando o grupo de amigos se diluiu, quando cada artista seguiu uma trajetória própria de carreira. Afinal, amizades se fomentam e se desfazem. Nas páginas finais do livro, há uma lista com as entrevistas e os depoimentos, concedidos à imprensa ou à autora entre 2008 a 2017, como os de Márcio Borges, Tavinho Moura e Fernando Brant. Tendo em vista o crescente universo de registros memorialísticos sobre o grupo - bem como as teses e as dissertações sobre o tema, elencadas por Sheyla Diniz -, deveria haver uma consideração teórica a respeito das condições contextuais desses artistas maduros falarem sobre suas experiências de juventude. Na luta por reconhecimento artístico e atribuição de prestígio, guardiões da memória também travaram batalhas para reservar lugar especial ao grupo musical, como a criação da Associação dos Amigos do Museu Clube da Esquina em 2004.

Sem manifesto fundador, o Clube da Esquina jamais se organizou como movimento cultural, nem como "panelinha" exclusivamente de artistas mineiros. Foi uma formação cultural sem participação formal de associados, mas com engajamento de seus participantes para a confecção coletiva de produtos culturais como os discos (p.127). Para o mercado fonográfico e a crítica especializada, no entanto, era mais simples definir segundo o lugar de origem e agrupar sob a liderança do artista de maior reconhecimento artístico e comercial: Milton Nascimento. A unidade no Clube da Esquina era uma "gama de pensamentos e sentimentos" (p.79), de elementos afetivos coletivos, que caracterizou a atuação desses artistas no mercado da música, suas relações pessoais e as respostas de suas atividades culturais às transformações na organização social e política. 
Apesar da recorrência do uso de expressões como a "turma" para se referir aos amigos, há poucas referências no livro a um debate sobre as relações entre as gerações - as "autoridades" e os "hereges" - nos circuitos artísticos. A diversificação de recursos estilísticos aparecia como marca indelével desses artistas mineiros. Na conturbada conjuntura de censura após o Ato Institucional n5, jovens como Salomão Borges Filho, com menos de 20 anos já envolvido com os álbuns Clube da Esquina e Lô Borges, ambos de 1972, embaralhavam as fronteiras daquilo que havia sido chamado de MPB. Essa sigla, quando a "turma" começou a se formar, já não era vista como imune às influências tidas como exógenas.

O Clube da Esquina, que teve 25 mil cópias vendidas em dois anos pelo preço de 44 cruzeiros, não era um manifesto de movimento cultural, mas uma "manifestação pública coletiva de um grupo amplo e heterogêneo de compositores, músicos e amigos" (p.127). A última faixa, “Ao que vai nascer”, composta por Milton Nascimento e Fernando Brant, foi censurada devido à "descrença" dos autores no futuro do país.

O Clube, sem carteira de sócio, nem sede, era uma "entidade imaginária" (p.264) que construía e reorganizava identidades em diferentes níveis: os laços de pertencimento dos amigos ao grupo, a definição sobre a "essência" das Minas Gerais, a relação entre regional, nacional e universal, a proximidade da realidade política brasileira com os demais países da América Latina. Os "mineiros", em perspectiva comparada, pareciam, para alguns operadores das classificações sobre música brasileira, pouco contestadores, inovadores ou esteticamente revolucionários - em suma, mais "caretas" -, abordagem contestada por Ronaldo Bastos, para quem o "movimento" foi mais universalista, em termos líricos e musicais, do que o "tropicalismo".

Embora abundantes e de natureza heterogênea, os dados expostos jamais tornam enfadonha a leitura, uma viagem intelectual que conta com seleção farta de imagens, sobretudo pareceres da censura, capas e contracapas de álbuns. Como um prisma, esse livro ajuda a compreender sociologicamente tipos de relações entre amigos, as conexões entre texto e contexto, as canções e as emoções daqueles intérpretes e compositores. 